UDC 811.111'272(497.6)

$81 ' 26$

\title{
Snežana Bilbija
}

University of Sarajevo, Bosnia and Herzegovina

\section{WHAT WILL THE OHR DISCOURSE BE REMEMBERED BY?}

\begin{abstract}
The main objective of this paper is to give an overview of linguistic properties of the political discourse produced by the Office of the High Representative (the OHR) in post-Dayton Bosnia. The paper concerns itself with morphological idiosyncrasies, syntactic choices, semantic presuppositions and kinds of metaphors contributing significantly to the promotion of the OHR ideology.
\end{abstract}

\section{Introduction}

According to numerous political speculations and predictions circulating in the political context of Bosnia and Herzegovina, it is expected that the Office of the UN High Representative ${ }^{1}$ will cease to exist in the course of 2009. The consequence of this will be the disappearance of the HR's powerful discourse which has since 1995 been the exclusive factor in shaping political life in BiH after the war (1992-1995). In the course of the past fourteen years, six appointed High Representatives have generated the same type of discourse organized round their undisputed political power. They also never failed to remind the Bosnian peoples of who has the "upper hand."

\footnotetext{
${ }^{1}$ The following quotation, containing the description of the role of HR, is posted in the official OHR website www.ohr.int: "In its resolution 1031 (of 15 December 1995), the Security Council endorsed the nomination of the High Representative to "monitor the implementation of the Peace Agreement and mobilize and, as appropriate, give guidance to, and coordinate the activities of, the civilian organizations and agencies involved" in the implementation of the Peace Agreement on Bosnia and Herzegovina. The Security Council also requested the Secretary General to submit reports from the High Representative, in accordance with Annex 10 of the Peace Agreement ".
} 


\section{Theoretical framework}

The present analysis of the data was conducted within the theoretical framework of Critical Discourse Analysis (henceforth CDA) as formulated primarily in the standard works of "the quartet" ${ }^{\text {" }}$ consisting of Teun van Dijk, Norman Fairclough, Ruth Wodak and Paul Chilton. ${ }^{3}$ In addition to enabling the analyst to detect the form and function of discourse structures arising from a particular social context, CDA presupposes that the analysis should include the identification of ideologies. Of course, within CDA there are numerous definitions of ideology. But if we compare van Dijk's definition of ideology according to which "an ideology is the foundation of the social representations shared by a social group" (Van Dijk 2006:728) with Chiapello and Fairclough 's claim that it is "a system of ideas, values and beliefs oriented to explaining a given political order, legitimizing existing hierarchies and power relations and preserving group identities" (Chiapello and Fairclough 2002:187), we can see that their respective views on ideology are practically identical.

\section{Analysis of the data}

The data was obtained from selected documents created in English by the High Representative himself, or in cooperation with his various associates. The documents are categorized as press releases, decisions, the HR's Speeches, the High Representative's Special Reports to the $U N^{4}$ and were all posted on the official OHR site in the course of 2007/08 and the first two months of 2009. We should seize upon this moment, right before the replacement of the OHR by a different Office, and make an overview of the linguistic facets of the OHR discourse. Why was the discourse of current HR Miroslav Lajčak chosen to represent the OHR discourse as such? The answer to this may be found in our conviction that in his discourse M. Lajčak, the sixth in the line of the High Representatives, seeks to retain the

\footnotetext{
2 This term is used by I. Blommaert (Blommaert 2005:21) to emphasize the four scholars' common contributions to CDA rather than their mutual differences.

${ }^{3}$ P.Chilton's writings significantly influenced my perception of CDA, apart from his recent views that the social grounding of CDA should be minimized if not completely abandoned.

${ }^{4}$ Current HR Mirolav Lajčak has so far submitted three Reports to the UN SecretaryGeneral since assuming the Office ofHigh Representative for Bosnia and Herzegovina and EU Special Representative on 1 July 2007.
} 
recognizable central idea that $\mathrm{BiH}$ needs the OHR, under the assumption that it cannot leave decision making to its politicians. Having inherited from the previous HRs a tacitly agreed upon linguistic rendering of OHR political objectives, the discourse of the current HR also mirrors numerous pragmatic reflexes of life in post-Dayton Bosnia which crept into this discourse during the fourteen-year-long rule of the OHR.

\section{OHR discourse ideology}

Rather than merely claiming that the OHR's discourse is ideological, this paper aims to closely examine the ways in which the OHR produces and reproduces its ideology through language. It is widely known that the most important world powers, posing under the UN "umbrella" established the OHR with the ambition to politically govern post-war Bosnia. In this way, it was publicly announced that the imposed rule of the OHR implies unequal distribution of political power and, equally importantly, that such rule has legitimacy. Therefore, any discourse generated by the only source of political power in Bosnia (the OHR) can be labeled ideological. It is therefore difficult to understand why the discourse of the OHR insists so vehemently on linguistically securing the UN licensed political inequality.

The OHR's political discourse abounds in various linguistic means used for the realization of its ideology and the following sections will concern themselves with the identification and description of such means.

\subsection{Linguistic realization of the OHR political discourse}

Our linguistic analysis of the current OHR discourse will begin with a morphological description since certain decisions that were made by discourse creators are not in agreement with mainstream practices in morphology.

\subsubsection{Morphology of the OHR discourse}

When the OHR discourse is examined from a morphological angle, it can be noted that this discourse is replete with ad hoc morphological 
solutions realized within such derivational morphological processes known as compounding and abbreviations. The appearance of unusual morphological derivatives in this discourse can be attributed to the idiosyncrasies of the Bosnian political context that had to be dealt with linguistically.

\subsubsection{Compounding}

We can start with the morphological realization of the country's name itself, which can be rendered in English in two ways: either as a hyphenated compound 'Bosnia-Herzegovina' or as a coordinated compound 'Bosnia and Herzegovina', which can be regarded as a calque or loan translation of the home term "Bosna i Hercegovina". The coordinated compound variant seems to be the only linguistic choice in the OHR texts in English

(1) Regrettably, this important step has not led to a change in the politics that are conducted in Bosnia and Herzegovina (HR's 34 Report to the UN)

\subsubsection{Abbreviations (initialisms)}

Abbreviations are often referred to as pet morphological forms of Contemporary English. Interestingly enough, the $\underline{\mathrm{BiH}}$ form, which is the $\mathrm{B} / \mathrm{C} / \mathrm{S}^{5}$ abbreviated form for the country's name, is borrowed unchanged into English, retaining the non-English conjunction i ('and').

(2) ...expresses its deep concern about the frequent challenges to the constitutional order of $\underline{\mathrm{BiH}}$ and, in particular... (Press release)

The adoption of an ad hoc morphological solution for the abbreviated form for the country's name Bosnia and Herzegovina in English can be contrasted with the three legitimate morphological abbreviating possibilities existing in English: BH, B-H and B\&H .

By looking at other morphological solutions for abbreviating those complex noun phrases used to name Bosnian political phenomena (ranging from political parties to different organizations) one finds cases where the full name of such political bodies is provided in the English translation, while

\footnotetext{
${ }^{5}$ The abbreviation $\mathrm{B} / \mathrm{C} / \mathrm{S}$ stands for the English translation of the 3 official languages in $\mathrm{BiH}$ : B stands for Bosnian, C for Croatian and S for Serbian. In the official text the letters always appear in this order.
} 
the abbreviated form is provided in the local B/C/S version. Illustrations of such cases are provided by examples (3) and (4) below.

(3) The leaders of both the Croatian Democratic Union of Bosnia and Herzegovina (HDZ BiH) and HDZ 1990... (Press release)

(4)...worth noting that the statement marks a distinct change of policy on the part of Dodik's ruling party Alliance of Independent $\underline{\text { Social Democrats }}$ (SNSD), which... (Press release)

The moment one is inclined to conclude that morphological possibilities for the abbreviations have been exhausted, one finds that in the OHR discourse it is possible for the abbreviated forms to appear without their full name preceding them (which would provide the interpretation for the abbreviations) as is shown in the example (5) below:

(5) Miroslav Lajčák met with the SDA President Sulejman Tihić in Sarajevo today to discuss the current political situation in Bosnia and Herzegovina, particularly the implementation of the agreement reached by the leaders of $\underline{\mathrm{HDZ}} \underline{\mathrm{BiH}}, \underline{\mathrm{SDA}}$ and $\underline{\text { SNSD in Prud... (Press release) }}$

On the other hand, when the complex names of other Bosnian institutions require abbreviation, the "normal" English abbreviation practice is implemented and the abbreviations are formed by stringing the initial letters of the constituent words in the complex name in English which is illustrated by examples (6) and (7) below.

(6) Ensuring the independence of the Communications Regulatory Agency ( $\underline{\text { CRA }) ~ i n ~ t h e ~ R S ~ i s ~ p a r t i c u l a r l y . . . ~(P r e s s ~ r e l e a s e) ~}$

(7) Miroslav Lajčák met today in Sarajevo with Chair of the Council of Ministers Nikola Špirić and addressed the regular session of the CoM to discuss the priorities on the EU agenda, which need to get back on track... (Press release)

How can this ad hoc morphology be accounted for? One thing is certain opting for the morphological solutions noted above does not stem from a collection of instructions recorded in some fixed and reliable language policy on English usage in BiH. Rather, it is a result of the 'arbitrary linguistic judgment' adopted by the offices that release various documents or statements.

The inconsistency of morphological decisions in the OHR discourse is even more salient when the name of BiH's smaller Entity, i.e. Republika 
Srpska ${ }^{6}$ is mentioned. In some instances of OHR written discourse this proper noun is used both with the definite article and without it as illustrated in examples (8) and (9) below.

(8) The merger is awaiting adoption by $\emptyset$ Republika Srpska of the necessary transitional legislation. (Press release)

(9) .. challenges to the existence of the Republika Srpska as one of two entities under the Constitution of BiH. (Press release)

The same indecisiveness regarding the use of definite article in front of the proper noun Republika Srpska affects the use of the article when the full name is abbreviated as in the example (10) below.

(10) ...implied an implicit recognition of the RS. (Press release)

In concluding this section on morphological diversity in the OHR discourse, it can be noted that the choice of unusual ad hoc morphological solutions was motivated by the desire of the creators of this discourse to make salient reference to the existing political factors in Bosnia. In this way, the OHR also demonstrates knowledge and, more importantly, control of the situation in the concrete Bosnian context. However, it could equally be justifiable to attribute this morphologically volatile behaviour to the OHR's disrespect for a possibly different linguistic solution.

\subsection{Syntactic characterization of the OHR discourse}

The remaining sections of this paper will continue to argue that OHR discourse is a textbook example of a genuine ideological discourse in which there is an adversarial relationship between We/Us and They/Them. Ideological adversaries are supposed to engage in a struggle out of which

\footnotetext{
${ }^{6}$ It is interesting to note that the proper name Republika Srpska apppeared as such for the first time in the Dayton Peace Agreement. It continued to be used as such in the official documents created by the OHR as well as other official institutions in $\mathrm{BiH}$, that go under the umbrella term of "the international community". Moreover, one may also often find the English hybrid translation of the original term rendered as "The Republic of Srpska" in a number of journalistic texts relating to Bosnia in the war period as well as to its post-war reality. This neologism could be justified by the existence of similar proper names for the names of countries like the Republic of Croatia and the People's Republic of China. What was the rationale behind the decision for the original "foreign" (Serbian) sounding name to be retained in all subsequent (post-Dayton) official English texts (as in the OHR's discourse and many others)? This appears even more mysterious since other home terms like Federacija BiH were translated as The BiH Federation. Perhaps it is wiser to look for possible answer in politics rather than in linguistics.
} 
the "Us" (the OHR = the good guys) is expected to come out as the winner. The implementation of the strategy of positive self-representation (the OHR) and negative Other-presentation (BiH politicians $=$ Them) is supposed to ensure this outcome. In such a discourse this strategy is executed through a plethora of syntactic choices, some of which, like passive and active uses of verbs, are illustrated in examples (11) and (12) and (13) and (14) below.

\subsubsection{Passive verb forms for negative Other-presentation}

(11) With regard to Herzegovina-Neretva Canton it proved necessary for me to set a deadline of 1 August to ensure formation a new cantonal government - ten months after the general elections. This deadline was met. (HR's 33 Report to the UN)

(12) In April, two police reform laws were adopted by the Parliamentary Assembly of Bosnia and Herzegovina. (HR's 34 Report to the UN)

\subsubsection{Active verb forms for positive self-presentation}

(13) ...the OHR will assist the domestic authorities in examining and applying these proposals. (HR's 34 Report to the UN)

(14) The Office of the High Representative successfully mediated a compromise for the adoption of the national justice sector reform strategy in June. (HR's 33 Report to the UN)

The ideological discourse of the OHR, like any other ideological discourse, makes use of passive sentences in order to minimize the positive things about the adversary. By removing the focus from responsible, positive agents, their praise-worthy achievements become intentionally depersonalized. Contrary to this, active sentences are always used to emphasize agents (OHR) and portray them explicitly as responsible subjects always ready to undertake an active role.

\subsection{The role of semantics in OHR ideological discourse}

The area of lexical semantics provides generators of any discourse the political in particular - with access to the semantic phenomenon known as semantic presuppositions. The intriguing aspect of semantic presuppositions is that they cannot be extracted from the concrete discourse as specific, salient structures. But they are released as meanings 
(propositions) by linguistic signals that trigger them. Levinson (1989:181185) gives a rather exhaustive list of presupposition triggers which range from definite descriptions to factive verbs to change of state verbs, etc. Because they are associated with what is not said, but is implied, presuppositions are very effective in the hands of discourse manipulators. Presuppositions allow the speaker or writer to question or challenge or attack something or someone and avoid responsibility for such actions. These are very effective linguistic devices for implementing the strategy of positive self-presentation and negative Other-presentation and Chilton (2007) defines them as follows:

Presupposition is of central importance to discourse analysts, and in particular to those concerned with elucidating what is not said, what is taken for granted and what is assumed to hold valid for a political community (Chilton 2007:297).

The following examples from the OHR discourse exemplify two propositions, one that is "visible" and contained in the example and the other that is triggered by a characteristic device. The fact that the parallel proposition is invisible does not mean that it cannot be understood as shown in (15) and (16) below.

\subsubsection{Presupposition for positive self-presentation:}

Change of state verb - trigger

(15) .. the OHR will continue to engage with the $\mathrm{BiH}$ authorities to secure the implication of the reform agenda, but progress will not come easily. (HR's 33 Report to the UN)

$<O H R$ has already been engaged with the BiH authorities to secure the implication ...... $>^{7}$

\subsubsection{Presupposition for negative Other-presentation:}

Definite description - trigger

(16) In close coordinate with other IC actors, OHR has worked over the reporting period with the BiH Ministry of Security, the State Investigation and Protection Agency (SIPA), the Border Police and the entity and cantonal interior ministries

\footnotetext{
${ }^{7}$ The symbol $<>$ is used here to accomodate the presupposition, while the trigger signal is underlined.
} 
and police forces to enhance their effectiveness, particularly in the fight against organized crime. (HR's 33 Report to the UN) (HR'S 32 Report to the UN)

$<$ Organised crime is being fought $>$

\section{The use of metaphor in HR's political discourse}

The texture of HR's political discourse would be deemed incomplete if metaphors employed in the discourse were not included in the critical elucidation of his language. In fact, metaphors are exceptionally convenient in political discourse to justify policies and define events. Chilton and Illyin (1993) state that "from a cognitive point of view, metaphors are used in communication, political included, and in order for us to understand problematic situations in terms of situations we understand and are familiar with" (1993: 9). In the same article they also say that "metaphors new and old tend to be built out of basic human concepts arising from bodily interaction with the environment: standing upright, being in a containing space, moving from one point to another" (ibid).

\subsection{The concept of the body moving from one place to a better place as the foundation for the "road metaphor"}

In the discourse of the current HR road metaphors are often exploited since his mandate coincides with the beginning of negotiations with the EU regarding the $\mathrm{BiH}$ status as its potential state member. The literal meaning of the word "road" is described in the COED as "a long piece of hard ground that people can drive along from one place to another". (Concise Oxford English Dictionary $11^{\text {th }}$ edition)

\subsubsection{Metaphor of "the road leading to the European Union"}

From the cognitive perspective the use of the road metaphor in HR discourse can be associated with the concept of a stretch of ground framed by edges which separate the road from 'what is not the road'. Thus, to opt for the former means to walk on ground that is contained and can be controlled. The road, being entrenched in a schema of a container, has, like 
any container, its physical boundaries, i.e. its beginning and its end. The movement on the road is very rarely undertaken without a plan and a hope that the progress on it will be a success. At the end of the road, if one is lucky, one can find oneself in front of a dream house and a garden and can be admitted, integrated into that domain, provided one is first approved by the guards at the entrance. The domain waiting at the end of the road is likened to the rainbow metaphor, reminiscent of the road in the sky, which, in the myth, ends with the pot of gold awaiting those who are good and motivated to reach it. It is not difficult to guess that these metaphors are used to familiarize the recipients with the favourable political, economic and geographical concept of the EU and all that it represents as shown in examples (17), (18), and (19) below.

(17) It remains a requirement for the road to Europe and the International Community is firmly committed to a multiethnic, editorially independent and financially sustainable public service that operates in the interests of all BiH's citizens. (Press release)

(18) This country could be more prosperous and it could be further along the European road, if it did not have to contend with obstructionist forces. (Press release)

(19) Nobody in the EU will ease the visa regime for a country that refuses to follow the European path. ${ }^{8}$ (Press release)

\subsubsection{Metaphor of "the rainbow and the pot of gold"}

This metaphor, in fact, may be interpreted as a derivative of the road metaphor.

(20) Our overarching objective $<$ RAINBOW $>$ is to make this country stable, prosperous, democratic and secure and a member of the EU. This is a process in which the whole of society must take part for it concerns everyone; it is a process that can continue until the country joins the EU." <POT OF GOLD> (Press release)

(21) The stance that parliamentary parties adopt will decide whether it is possible to open the European Perspective

\footnotetext{
8 The fact that the HR sometimes uses the word "path" as a synonym for the word "road" does not affect the function and understanding of the road metaphor.
} 
$<$ RAINBOW $>$ for $\mathrm{BiH}$ and its citizens," said the High Representative and EU Special Representative, Miroslav Lajčák. (Press release)

(22) However, with the road to Europe <RAINBOW> currently blocked, it is incumbent on us to act - robustly and creatively to accelerate improvements in the daily life <POT OF GOLD $>$ of the people of Bosnia and Herzegovina, to deescalate the crisis that has been created. (Speech given by High Representative to the UN Security Council 2007)

\section{Conclusion}

As stated earlier, the OHR discourse as political discourse is by definition ideological, which implies that it is dialogic too. However, ideologies cannot be disseminated without the existence of a receiving Other. In this geopolitical environment, that Other appears to be the Bosnian society. It remains to be seen whether the future exclusive presence of the Office of the European Special Representative in Bosnia and Herzegovina will impose a different type of discourse. But judging from the text of the "Introduction" to the EUSR's Mission" in which it says that

the ultimate aim is to help ${ }^{10}$ Bosnia and Herzegovina evolve into a stable, viable, peaceful and multiethnic country, cooperating peacefully with its neighbours and irreversibly on track towards EU membership. (The EUSR homepage, March 2009),

it is more likely than not that we will be having the same kind of discourse all over again.

\section{References}

Blommaert, J. (2005). Discourse: A Critical Introduction. Cambridge and New York: Cambridge University Press.

Blommaert, J. (2006). Language ideology. In: Elsevier Encyclopedia of Language and Linguistics ( $2^{\text {nd }}$ edn.) Amsterdam: Elsevier Publishers. 510-522.

\footnotetext{
9 The Office of the European Union Special Representative homepage currently occupies half of the OHR's homepage (www.ohr.int)

${ }^{10}$ The italics are mine.
} 
Chiapello, E and N. Fairclough (2002). Understanding the new management ideology: a transdisciplinary contribution from critical discourse analysis and the new sociology of capitalism. Discourse and Society 13 (2): 185-208.

Chilton, P. and M. Ilyn (1993). Metaphor in political discourse. Discourse and Society 4 (7): 7-3.

Chilton, P and C. Schäffner (1997). Discourse and politics. In: T. A van Dijk (ed.), Discourse as Social Interaction. London: Sage. 206-230.

Chilton, P. (2004). Analyzing Political Discourse. London: Routledge.

Chilton, Paul (2007). Challenges in the study of language and politics. Journal of Language and Politics 6: 297-301.

Chouliaraki, L. and N. Fairclough (1999). Discourse in Late Modernity. Rethinking Critical Discourse Analysis. Edinburgh: University Press.

Fairclough, N. (1989). Language and Power. London:Longman.

Fairclough, N. (1992). Discourse and Social Change. Oxford, UK and Cambridge, MA: Polity Press and Blackwell.

Fairclough, N. (1995). Critical Discourse Analysis: the Critical Study of Language. London and New York: Longman.

Fairclough, N. and R. Wodak (1997). Critical discourse analysis. In: T. A van Dijk (ed.) Discourse as Social Interaction. Discourse Studies: A Multidisciplinary Introduction, Vol. 2. London: Sage. 258-284.

Fairclough, N. (2000). New Labour, New Language? New York: Routledge.

Lakoff, G and M. Johnson (1980). Metaphors We Live By. Chicago: Chicago University Press.

Levinson, S. C. (1989). Pragmatics. Cambridge: Cambridge University Press.

van Dijk, T. (1993). Critical Discourse Analysis. Special Issue of Discourse and Society, 4 (2).

van Dijk, T. (2006). Politics, ideology and discourse. In: Elsevier Encyclopedia of Language and Linguistics ( ${ }^{\text {nd }} \mathrm{edn}$.). Amsterdam: Elsevier Publishers. 728-740.

Wodak, R. and M. Meyer (eds.) (2001). Methods of Critical Discourse Analysis. London: Sage.

Wodak, R. (2006). Politics and language: Overview. In: Elsevier Encyclopedia of Language and Linguistics ( ${ }^{\text {nd }}$ edn.). Oxford: Elsevier Publishers. 707-719. 